\title{
A Review of SCUBA Diving Impacts and Implication for Coral Reefs Conservation and Tourism Management
}

\author{
Siti Zulaiha Zainal Abidin ${ }^{1}$, Badaruddin Mohamed $^{2}$ \\ ${ }^{1}$ Sustainable Tourism Research Cluster, Universiti Sains Malaysia, 11800, Penang, Malaysia \\ ${ }^{1,2}$ School of Housing, Building and Planning, Universiti Sains Malaysia, 11800, Penang, Malaysia
}

\begin{abstract}
Dive tourism has become important in term of magnitude and significantly contributes to regional economies. Nevertheless, in the absence of proper controls and enforcement, unplanned tourism growth has caused environmental degradation which undermines the long-term sustainability of the tourism industry. The purpose of this paper is to explore factors that contribute to the SCUBA diving impacts on coral and fish communities. This paper explains the causes of a certain event, validating the problem of impacts, defining the core issues and identifies possible causes leading to an effect. The phenomenon of diving impacts on coral reefs is a result of intensive use of dive site over the long-term. The divers can reduce their impacts towards coral reefs through responsible diving behaviors. The causes of cumulative diver's contacts are more complicated than it seems. In response, this paper proposes the best mitigation strategies that need to be considered for future dive tourism management.
\end{abstract}

\section{Introduction}

Marine tourism or tourism based on ocean and coral reefs is an important component of the global tourism industry and is rapidly growing than any other tourism sector particularly in many tropical countries [1]. The increasing interest in marine tourism can be considered at two levels. First, specific locations have become popular settings for marine based recreation, and second, specific marine recreational activities themselves have become popular. Marine tourism has been thought of as a sustainable option for coral reef use, compare to extractive practices such as the harvesting of corals and fish for commercial purposes [2-3]. However, concrete evidence has demonstrated that reefs become degraded and possibly compromise the amenity value of dive site as a result of poorly planned or intensive tourist use [4]. Marine tourism has been shown to affect reefs in two ways: direct effects on coral communities through accidental disturbance such as coral breakage, boats colliding with reefs and anchor damage [3] and indirect effects through alteration of water quality in the form of nutrient enrichment and the addition of pollutants such as toxic substances, wastewater and increased turbidity [3,5]. The intensity of impact is related to the frequency or amount of use, the type of use and associated behaviors, and the season of use and the environmental conditions or location [6].

Dive tourism is a special interest tourism that offers SCUBA (Self-contained Underwater Breathing Apparatus) diving as a primary activity during a vacation stay. SCUBA diving activities require special outfit that comes with some additional equipment such as cylindrical tank that stores compressed oxygen gas, mask and foot fins. A SCUBA diver can stay underwater longer than other forms of dives. This activities requires theoretical courses and specialized training to acquire the 
essential skills that are in a comfortable situation with the environment on the seabed and thus feel safe and enjoy the expedition dives. SCUBA diving usually occurs in marine locations less than $30 \mathrm{~m}$ deep, with impressive underwater scenery, novel features, such as shipwrecks, or high biological diversity. Over the last two decades, many tropical countries have developed significant recreational dive industries as divers have become aware of the beauty and comfort of diving in tropical environments [2,7-8]. Brander et al. [9] Indicated Southeast Asia to be one of the top diving destinations in the world and the expansion of coral reef recreation there to be of high economic value. Dive tourism, as other types of tourism, can bring economic benefits, improve quality of life at the destination, foster community pride, allow cultural exchange, reduce over-exploitation and promote conservation. Dive tourism became an essential part of international and domestic travel in Malaysia. Malaysian government identifies dive tourism as one of the high yield components of marine tourism and is aggressively promoting tourism icons such as Sipadan Island and Tunku Abdul Rahman Marine Park as a world-class SCUBA diving destination. Financial gains through investment and employment opportunities from the diving industry significant contribute to regional economic [10-11]. Diving lessons and certification, equipment rentals, dive tours, and diving accessories being easily available from coastal dive centers have made this activity more affordable and accessible even to remote parts of the world. As coral reefs are the major attraction for SCUBA divers, the degradation of coral reefs can potentially lead to the dissatisfaction of tourists and subsequently pose negative impacts on local tourism businesses.

To establish Malaysia as a tourist destination renowned SCUBA diving in the world, the challenges and constraints preserve the sustainability of diving destination must be addressed and rectify from its source. Nevertheless, in the absence of proper controls and enforcement, unplanned tourism growth has caused environmental degradation which undermines the long-term sustainability of the tourism industry. To address the above research problems, this study aimed to: (1) examine recreational SCUBA diving impact on coral and fish communities, (2) explore factors that contribute to the intensity of SCUBA diving impacts and (3) in response, this paper also proposes the best mitigation strategies that need to be considered for sustainable management of dive tourism. Therefore, in this endeavor, this paper will explains the causes of a certain event, validating the problem of impacts, defining the core issues and identifies possible causes leading to an effect.

\section{SCUBA Diving Impacts on Coral Reefs}

Coral reefs are underwater structures made from calcium carbonate secreted by corals. Most coral reefs are built from stony corals, which in turn consist of polyps that cluster in groups or colonies. The polyps belong to a group of animals known as Cnidaria, which also includes sea anemones and jellyfish. Unlike sea anemones, coral polyps secrete hard carbonate exoskeletons which support and protect their bodies. Reefs grow best in warm, shallow, clear, sunny and agitated waters. Coral reefs provide a home for $25 \%$ of all marine species and deliver ecosystem services to tourism, fisheries and shoreline protection. The annual global economic value of coral reefs is estimated between US\$29.8375 billion or equal to Ringgit Malaysia 96.18-1210.26 billion.

At present, coral richness is declining as a result of natural phenomena and anthropogenic activities. Globally, 36 percent of all reefs have been classified as threatened by overexploitation, 30 percent by coastal development, 22 percent by inland pollution and erosion, and 12 percent of marine pollution [12]. The threat to the health of the reefs is particularly high in Southeast Asia, where 95 percent of reefs are considered to be within the range of medium to very high risk of damage from local threats [13]. Red Sea experienced an increase of dive tourism produced major impacts from reef infilling for resort constructions and direct contacts by divers on the reefs [14]. Corals in Great Barrier Reef (GBR) encountered tremendous damages an excessive number of divers. In Malaysia, the scenario of the coral damage was quite similar to other countries as islands like Redang, Pulau Payar as well as Perhentian experienced coral damage due to resort development and uncontrolled diving behavior. In general, studies show nearly one third of the reefs in Malaysia have between 25 to $50 \%$ 
live coral cover, very few reefs with more than $75 \%$ live coral cover, and over $85 \%$ of the reefs are threatened by human activities.

Divers play a crucial role in marine environmental conservation as they're present in these vulnerable ecosystems may harm coral and fish communities [15-16]. Coral populations at the heavily dived sites are deteriorating, and current conservation policies for these sites appear to be ecologically unsustainable. There was also more dead coral and coral rubble at the site experiencing the greatest increase in diving [17]. Divers' impact on coral reefs has been widely documented in many areas of the world [15]. Some studies on diving impact have shown that raising sediment was the most frequent effect produced by divers, followed by contact with fragile organisms such as gorgonians, corals and bryozoans [16, 18-19]. The combination of these two effects is the main stressor agent which the benthic communities are subjected to by diving activity [20]. Despite the impacts of sunscreens and insect repellents on the reef are not yet clearly understood, Danovaro et al. claims that diver's sunscreens causes coral to be infected with a virus causing coral bleaching [21].

When divers swim too close to the coral, they may inadvertently stir up benthic sediment thereby subjecting coral polyps to increased sedimentation loads. These processes will affect corals through several mechanisms and some of them can be lethal and/or sublethal, such as: asphyxia, reduction in growth rates of the coral skeleton, abrasion, recruitment inhibition, reduction on live coral cover, changes on coral zonation, a greater abundance of branching corals or the dominance of colonies with small sizes [22]. Sedimentation on rocky coralligenous assemblages has been considered as a factor influencing their spatial and temporal variability. A recent monitoring study showed that in sites with high SCUBA diving frequency, $H$. papillosa abundance is very low. Reduction of coral growth may occur when precipitation of calcium carbonate to form the coral skeleton is altered by deficiency of available light (due to excess of suspended sediment in the water column), to the endossimbiont algae (zooxanthellae) that makes photosynthesis, or due to the excess of energy that the corals use to remove sediment from their polyps. Yet, corals also can be killed as well as due to the presence of pollutants carried by muddy solutions.

Divers may unintentionally injure stony corals and other sessile benthic organisms by breaking their skeletons and abrading their tissues [16]. Coral breakage affects biological processes such as growth and sexual reproduction [24]. Some scientists believe that even a simple touch by divers to the coral can trigger a syndrome called "Shut down reaction" where the coenosarcs (the layer of living tissue overlying the coenosteum) sloughs off the skeleton leaving behind a denuded skeleton or removal of the protective mucus produced to protect corals from all kinds of harmful which subsequently make them prone to diseases. Rates of coral tissue damage by predators and other agents on branching stony corals are much higher at heavily dived sites than at a protected reef site, leading to drastically reduced coral growth. This is a particular problem for coral, as damage is likely to take decades to repair, due to slow and limited regeneration capabilities [25]. However, skeletal breakage was not the major cause of damage to branching corals here. The impacts of divers on these coral communities were complex, and lead indirectly to increased predatory attack on the corals due to the repeated creation of tissue lesions and possibly compromised physiological condition [16, 25]. Coral communities are affected by dive tourism may depend in part on the susceptibility of each coral species to pathogens and predators that take advantage of physiological stress.

Previous studies showing that the effects of recreational diving on coral reefs depend on a variety of interacting factors. Coral communities dominated by branching corals are especially susceptible to diver damage due to their delicate and fragile structure $[16,28]$. However, the abundance of massive corals also may be reduced at the heavily-dived sites due to their relatively slow rates of growth and regeneration following repeated damage, in comparison with branching corals [26]. Thus, some diving-impacted coral reefs may experience a reduction in hard coral cover due to a loss of branching corals, while others may lose massive coral cover. Moreover, some coral communities may experience no change or even an increase in coral cover due to the proliferation of weeds opportunistic coral species that take advantage of the reduced abundance of superior competitors [26, 29]. The susceptibility of any given coral community to intensive recreational diving and repeated coral injury, thus depends on local environmental conditions, community structure, and the types of coral predators and pathogens. 
In a study in South Africa coral reefs, the densities of the top-level predator, E. tukula was a decline in the intensive use dive site. E. tukula is a large resident predator known to show aggressive territorial behavior towards divers on reefs isolated from human activities. Thus, the persistence of SCUBA divers on the intensive use dive site may be causing a competitive disturbance to E. tukula. Simultaneously, the higher abundances of herbivores fish juveniles such as Acanthurus coeruleusand Sparisoma sp. Suggest that the reef is under a higher level of human interference, since the high abundance of these species in marine ecosystems may indicate a sign of coral degradation due to the higher biomass of algae. Whether by artificially feeding the fishes or by trampling over the substrate, recreational activities benefiting one or a few species, with harsh impact on others. Therefore, it is common to observe a pattern shifting from common, abundant species and a progressive decline to rarer species [27]. As consequences, fish assemblage structure has been intensively modified.

\section{Divers Underwater Behaviour}

Individual divers may vary widely in behaviour and in the amount of damage that they may cause [30]. Although the damage done by individuals is often small, there is some evidence can cause significant localized destruction of sensitive marine organisms [26]. The diver can reduce their impacts towards coral reefs through responsible diving behaviour. The causes of cumulative diver's contacts are more complicated than it seems as show in Figure 1 [31]. According to the standard requirements for recreational SCUBA diving proposed by ICRAN MAR 1 [32], divers shall accordance with all applicable local and national laws and regulations on diving activity. The guidelines include maintaining an awareness of fins, equipment and cameras; adjust buoyancy, and secure equipment to avoid contacting corals or stirring up sediment while diving. Divers shall not touch or contact corals or other reef dwelling organisms; spear any marine life, swim close, chase, or harass marine life such as sea turtles; feed fish or any other marine life.

Divers could cause harm to corals via direct physical contact by touching or walking on them, kneeling, standing or dragging and snagging of equipments and some of diver may even accidentally kick corals with their fin when they lose their buoyancy $(58 \%)$ or deliberately holding onto corals $(32 \%)$ [30]. One research reported that around $90 \%$ of divers had one or more physical interactions with reef benthos. Studies agreed that fins cause most damage to the corals followed by hands, knees and equipment $[18,30]$. In this research, he found that $46 \%$ of the drivers admitted holding on to the corals during dives in strong currents. Also, $67 \%$ of the drivers admitted damaging corals in their earlier dives.

Previous research on level of specialization suggests that an increase in activity involvement leads to more positive attitudes toward environmental concerns and more prominence among divers on the natural preservation. Expert divers are more aware of specific environmental issues rather than general environmental issues. For instance, expert divers are more likely to aware of the negative impacts of their activities and they favour low-impact practices [33]. The number of contacts with corals declined with the increasing diver experience with a trend towards fewer contacts with advanced diver training. Likewise, expert divers tend to have better skills than beginners do and are more focused on the activity they are involved in. Photographers and the less experienced divers were also seen to have collided more with the corals in the study conducted by Walters and Samways [35] in the South African coral reef. Expert divers can mitigate impacts to coral reefs by moving through the water with proper buoyancy and fin techniques. It appears that all divers can protect corals by avoiding physical contact with them [34]. 


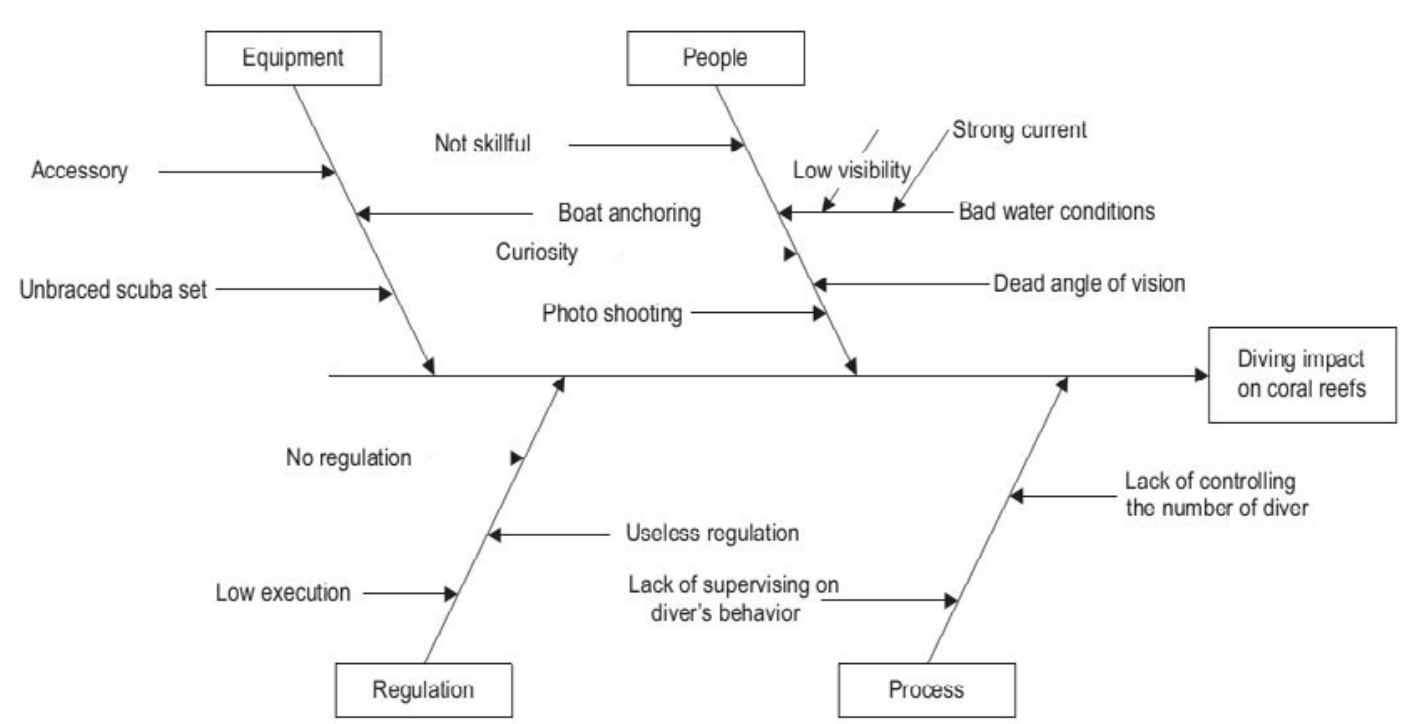

Figure 1. The SCUBA Diving Impact on Corals Reefs Illustrated by a Fishbone Diagram.

\section{Mitigation Strategies}

The sustainability of dive tourism requires not only the conservative use of natural and social resources, but also economic viability of all stakeholders, community integration and the provision of satisfying diving experiences. There is no perfect planning or policy process which can be easily translated from one dive tourism management jurisdiction to another. Each diving site needs to select the appropriate strategies for its own development requirements. It's unique characteristic, coupled with other issues facing the dive tourism industry (i.e. the absence of regulation, limited capacity of the local government, lack of horizontal, vertical and international integration, inactive involvement of all stakeholders, multi-cultural society with heterogeneous attitudes, and being an island destination with dynamic systems and geographical limitations) has made the implementation of strategic management approaches nearly impossible.

Over the past decade, in an effort to alleviate negative impacts of divers on the reefs, varieties of management framework recommendations have been offered by researchers. Unfortunately, current management frameworks have major limitations, particularly for developing countries. These suggestions include limiting the numbers of visitors to diving sites, promoting site substitution policies, using artificial reef, educating low-impact recreational practices [36] and enforcing park rules and regulations. However, the impacts of divers can be influenced by a number of factors, including diver education, reef composition and topography, and infrastructure development near the dive site. Nonetheless, Rouphael \& Inglis [30] suggested that it would be more realistic and efficient to identify and mitigate the causes of damaging behavior of divers rather than using other methods. Several researchers have stressed that the damage on coral reefs caused by divers can be minimized by changing the behavior of divers.

Diver carrying capacity is usually expressed as a maximum number of dives per site per year, and is a measure of the number of dives a site can sustainably support without becoming degraded. When diving rate is below carrying capacity for a given reef site, coral damage is minimal, but above carrying capacity, coral damage may increase greatly. Recently, a controversy exists concerning the carrying capacity of different types of reefs for recreational SCUBA diving, and the concept of possible threshold levels of diving above which use is unsustainable over the long term [15]. Diver carrying capacity appears to depend on a combination of factors that vary between sites, including: (1) the morphological composition of coral (the presence of vulnerable types of organisms, such as branching stony corals and sea whips), (2) the level of environmental awareness and training 
(specialization level) of the divers involved, (3) the presence of other anthropogenic stressors that degrade the reef, such as particulate pollution, and (4) the size of the dive site, reef topography (gentle sloping, flat reefs or reefs with vertical drop off), current patterns, and other form of exploitations that occurs over the same reef. All this factor needs to be considered for each dive sites before maximum number of dives per site per year estistimated and apply. Continual adjustment of diver carrying capacity will depends on annual assessment of dive sites.

The Green Fins approach is a tool for supporting adoption and implementation of best practice through a set of diving standards. This project was initiated in 2004 by the UNEP as part of an effort to reduce unsustainable coastal tourism practices in the region. To date, the project has been introduced in four countries; Indonesia (2007), Malaysia (2008), the Philippines (2010) and Thailand (2004). The Green Fins initiative has developed a comprehensive set of guidelines to encourage best practice for an environmentally sustainable scuba diving industry, which is known as the Green Fins Code of Conduct (COC). However, until now there has been no practical system to implement these guidelines, nor for monitoring their success [37], plus a lack of internal and external support (including legislative action, funding and academic contribution) is a significant issue. After 6 years was introduced and various efforts have been made, but the program does not show the desired outcome.

The combination of this two modified approch seem to the best mitigation strategy can be applied in Malaysia. Mitigation strategy needs to integrate a variety of stakeholders in its approach in order to manage the numerous conflicting activities that occur within the marine environment as this is a crucial part of the system providing long term sustainability [37].

\section{Conclusion}

In order to minimize tourism-induced problems and secure both the sustainability of the tourism industry and coastal resources used by other sectors, it is crucial that tourism is planned, developed and operated within the context of sustainable development principles. A number of scholars have advocated management approaches to overcome the unsustainable management of the dive tourism industry. Effective conservation requires mitigation of the negative impacts of diving, derivation of increased benefits and increased understanding of their nature and distribution, and implementation of effective management interventions to reduce negative impacts and expand benefits [3]. Sustainable management in dive tourism requires a multidisciplinary approach [38]. Knowledge of diver impacts was gained by examining the carrying capacity of dive sites [16, 39-40], as well as studying divers' demographic and behavioral characteristics to see whether certain categories of divers caused more negative impacts than others $[18,30,41]$, and eliciting the types of intervention that might alter divers' underwater behavior $[18,30]$. The assessment system in the Green Fins approach is effective and useful for tailoring the management initiative to specific resorts and regions. Its support and guidance offered through consultations, marine education and the incentives involved in complying with the codes of conduct have been shown to encourage dive centers to mitigate their threat to marine ecosystems.

\section{Acknowledgement}

The authors would like to extend their appreciation to the Ministry of Higher Education, Malaysia for granting the Long Term Research Grant Scheme 2011 [LRGS Grant No. JPT.S (BPKI) 2000/09/01/015Jld.4 (67)] that made this study and paper possible. 


\section{References}

1. M. Bennett, P. Dearden, R. Rollins, The sustainability of dive tourism in Phuket, Thailand. In Communities in SE Asia: Challenges and Responses, 97-106, (2003)

2. M. Milazzo, R. Chemello, F. Badalamenti, R. Camarda, S. Riggio, The impact of human recreational activities in marine protected areas: what lessons should be learnt in the Mediterranean sea?, Mar. Ecol., 23, 280-290 (2002)

3. P. Dearden, M. Bennett, R. Rollins, Perceptions of diving impacts and implications for reef conservation, Coast. Manage., 35, 305-317 (2007)

4. H. Hasler, J. Ott. Mar, Diving down the reefs? Intensive diving tourism threatens the reefs of the northern Red Sea. Pollut. Bull., 56, 1788-1794 (2008)

5. P. Reopanichkul, T.A. Schlacher, R.W. Carter, S.Worachananant, Sewage impacts coral reefs at multiple levels of ecological organization, Mar. Pollut. Bull., 58, 1356-1362 (2009)

6. J. Priskin, Tourist perceptions of degradation caused by coastal nature-based recreation, Env. Manag., 32, 189-204 (2003)

7. M.A. Rudd, M.H. Tupper, The impact of Nassau grouper size and abundance on scuba diver site selection and MPA economics Coast. Manage., 30, 133-151(2002)

8. G. Musa, K. Dimmock, Scuba diving tourism: introduction to special issue, Tou. Mar. Env., 8, 1$5(2012)$

9. L.M. Brander, P.V. Beukering, H.S.J. Cesar, The recreational value of coral reefs: a metaanalysis, Ecol. Econ., 63, 209-218 (2007)

10. C. Oh, R.B. Ditton, J.R. Stoll, The Economic Value of Scuba-Diving Use of Natural and Artificial Reef Habitats, Soc. Natur. Resour., 21, 455-468 (2008)

11. I.M. Shaalan, Sustainable tourism development in the Red Sea Egypt threats and opportunities, Clean. Pro., 13, 83-87 (2005)

12. L. Burke, E. Selig, M. Spalding. Reefs at riskin Southeast Asia., (2002)

13. L. Burke, K. Reytar, M. Spalding, A. Perry, Reefs at Risk Revisited., (2011)

14. D. Zakai, N.E. Chadwick-Furman, Impacts of intensive recreational diving on reef corals at Eilat, northern Red Sea. Biol. Conserv., 105, 179-187 (2002)

15. J.A. Tratalos, T.J. Austin, Impacts of recreational SCUBA diving on coral communities of the Caribbean island of Grand Cayman, Biol. Conserv., 102, 67-75 (2001)

16. L. Mastny, A world watch addendum on coral reef, World Watch., 14, $20-21$ (2001)

17. C. Wilkinson. Status of coral reefs of the world: summary of threats and remedial action (2006).

18. N.H.L. Barker, C.M. Roberts, Scuba diver behaviour and the management of diving impacts on coral reefs, Biol. Conserv., 120, 481-489 (2004)

19. B. Luna, C. Valle Pérez, J.L. Sánchez-Lizaso, Benthic impacts of recreational divers in a Mediterranean Marine Protected Area, Mar. Sci., 66, 517-523 (2009)

20. P. Chabanet, M. Adjeroud, S. Andrefouet, Y.M. Bozec, J. Ferraris, J.A. Garcia-Charton, M. Schrimm, Human-induced physical disturbances and their indicators on coral reef habitats: a multi-scale approach, Aquat. Living. Resour., 18, 215-230 (2005)

21. R. Danovaro, L. Bongiorni, C. Corinaldesi, D. Giovannelli, E. Damiani, P. Astolfi, Sunscreens cause coral bleaching by promoting viral infections, Env. Health. Perspect., 116, 441-7 (2008)

22. D.R. Bellwood, T.P Hughes, Regional-scale assembly rules and biodiversity of coral reefs, Sci., 292, 1532-1534 (2001)

23. D. Zakai, O. Levy, N.E. Chadwick-Furman, Experimental fragmentation reduces sexual reproductive output by the reef-building coral Pocillopora damicornis, Coral. Reefs., 19, 185-188 (2000)

24. J. Davenport, J.L. Davenport, The impact of tourism and personal leisure transport on coastal environments: a review, Estuar. Coast. Shelf. S., 67, 280-292 (2006)

25. J.P. Hawkins, C.M. Roberts, T. van't Hof, K. de Meyer, J.A. Tratalos, C. Aldam, Effects of recreational SCUBA diving on Caribbean coral and fish communities, Conserv. Biol., 13, 888-897 (1999) 
26. R.P. Medeiros, R.G. Grempel, A.T. Souza, M.I. Ilarri, C.L.S. Sampaio, Effects of recreational activities on the fish assemblage structure in a northeastern Brazilian reef, Aquat. Sci., 2, 288300 (2007)

27. K.S. Rodgers, E.F. Cox, The effects of trampling on Hawaiian corals along a gradient of human use, Biol. Conserv., 112, 383-389 (2003)

28. A.B. Rouphael, G.J. Inglis, Increase spatial and temporal variability on coral damage caused by receational scuba diving, Ecol. Appl., 12, 427-440 (2002)

29. T. Rouphael, G.J. Inglis, 'Take only photographs and leave only footprints'?: an experimental study of the impacts of underwater photographers on coral reef dive sites, Biol. Conserv., 100, 281-287 (2001)

30. K.C. Ku, T.C. Chen, A conceptual process-based reference model for collaboratively managing recreational scuba diving in Kenting National Park, Mar. Poll, 39, (2013).

31. ICRAN MAR 1. Standard requirements for recreational scuba diving services in the Mesoamerican reef system., (2006)

32. G. Musa, W.T. Seng, T. Thirumoorthi, M. Abessi, The influence of SCUBA divers' personality, experience, and demographic profile on their underwater behaviour, Tourism. Mar. Env., 7, 1-14 (2011)

33. B. Thapa, A.R. Graefe, L. Meyer, Moderator and mediator effects of SCUBA diving specialization on marine-based environmental knowledge-behaviour contingency, Environ. Educ., 37, 53-67 (2005)

34. R.D.M. Walters, M.J. Samways, Sustainable dive ecotourism on a South African coral reef, Biol. Conserv., 10, 2167-2179 (2001)

35. C. Townsend. Marine ecotourism through education: A case study of divers in the British Virgin Islands. In Marine ecotourism: Issues and Experiences., 138-154 (2003)

36. C.V. Hunt, J.J. Harvey, A. Miller, V. Johnson, N. Phongsuwn, The Green Fins approach for monitoring and promoting environmentally sustainable scuba diving operations in South East Asia, Ocean \& Coast. Manag., 78, 35-44 (2013)

37. P. Stolk, K. Markwell, J.M. Jenkins, Artificial reefs as recreational scuba diving resources: a critical review of the research, J. Sustain. Tour., 15, 331-350 (2007)

38. A.B. Rouphael, M. Hanafy, An alternative management framework to limit the impact of SCUBA divers on coral assemblages, Sus. Tou., 15, 91-103 (2007)

39. M.H. Schleyer, B.J. Tomalin, Damage on South African coral reefs and an assessment of their sustainable diving capacity using a fisheries approach, Bull. Mar. Sci., 67, 1025-1042 (2000)

40. M.G. Sorice, C. Oh, R. Ditton, Managing SCUBA divers to meet ecological goals for coral reef conservation, Ambio., 36, 316-322 (2007) 